\title{
Formação de educadores do campo na Amazônia amapaense: um estudo sobre o Procampo na UNIFAP
}

\author{
Heliadora Georgete Pereira da Costa ${ }^{1}$ e Roni Mayer Lomba ${ }^{2}$
}

\footnotetext{
1 Mestrado em Desenvolvimento Regional - PPGMDR, Especialização em Gestão Escolar - ULBRA e Graduação em Pedagogia - UFPA, Brasil. E-mail: heliadoracosta@gmail.com

2 Doutor em Geografia Humana pela USP. Professor adjunto do Colegiado de Geografia e Professor Permanente do Mestrado em Desenvolvimento Regional da UNIFAP, Brasil. E-mail: ronimayer@hotmail.com
}

RESUM O: Este artigo tem por objetivo apresentar resultados da pesquisa sobre a formação inicial dos docentes das escolas do campo realizada nos cursos de Licenciatura em Educação do Campo conveniados com o Programa de Apoio à Formação Superior em Licenciatura em Educação do Campo (PROCAMPO) e a Universidade Federal do Amapá (UNIFAP). É uma abordagem qualitativa, cuja metodologia constou de pesquisa documental com a análise de editais, projetos pedagógicos e o memorial dos cursos do Procampo e a pesquisa de campo com a aplicação de questionários e entrevistas semiestruturadas direcionadas aos egressos e docentes, a fim de discutir a materialização e os impactos dessa política na formação dos professores no Estado do Amapá. A análise dos dados revelou, de um lado, que a Licenciatura em Educação do Campo implantada na UNIFAP é um importante desafio para a instituição devido à falta de tradição com este modelo de licenciatura e, de outro, como um avanço para as políticas educativas de formação dos trabalhadores do campo.

Palavras-chave: Educação do campo. Procampo. Formação. Política pública.

\section{Countryside teachers formation in the Amazon from state of Amapá: a study on the Procampo Unifap}

ABSTRACT: This article aims to present research results on the initial training of teachers in countryside schools, conducted in the Countryside Education Degree courses insured to Support Higher Education Program Degree in Rural Education (PROCAM PO) and the Federal University Amapá (UNIFAP). It is a qualitative approach whose methodology included desk research with the analysis of bids, educational projects and the memorial of Procampo courses and field research. It was due with the application of questionnaires and semi-structured interviews directed to graduates and teachers in order to discuss the materialization and the impact of this policy on the training of teachers in the state of Amapá. Data analysis revealed that, on the one hand, the degree of Countryside Education located in UNIFAP is a major challenge for the institution due to lack of tradition with this degree model and the other, as a breakthrough for educational policy training of countryside workers.

Keywords: Countryside Education. Procampo. Formation. Public policy.

\section{INTRODUÇÃO}

Este texto apresenta resultados da pesquisa intitulada "Políticas Públicas de Educação: um estudo sobre os Programas Federais de Educação para o Campo no Amapá", cujas observações e análises possibilitaram a compreensão de que a Educação 
do Campo é um paradigma em construção que expressa-se nas lutas dos movimentos sociais camponesas.

0 objetivo da pesquisa foi analisar o desenvolvimento da formação inicial dos professores, a partir da implantação do curso de Licenciatura em Educação do Campo (LEDOC) na UNIFAP apoiada pelo Programa de Apoio à Formação Superior em Licenciatura em Educação do Campo (PROCAM PO). Os questionários e, principalmente, as narrativas dos sujeitos obtidas por meio das entrevistas revelaram o envolvimento pessoal e profissional dos acadêmicos com as questões relativas à educação no contexto amapaense, o que relaciona-se ainda às experiências que tomam referências em seus grupos sociais, seja família, escola, comunidade, sindicatos e associações rurais.

O Procampo foi um programa de financiamento que teve como finalidade apoiar projetos de Licenciaturas em Educação do Campo nas instituições de ensino superior (IES) públicas do País. Os cursos conveniados ao Procampo tinham como objetivo prioritário promover a formação, em nível superior, de educadores que atuam nas escolas do campo em todo o Brasil.

A proposta dos cursos de LEDOC/Procampo foi elaborada pelo Grupo Permanente de Trabalho de Educação do Campo (GPT) ou Comissão Nacional de Educação do Campo (CONEC) e sua implementação ocorreu em 2007, por meio de projeto piloto implantado na Universidade de Brasília (UNB), Universidade Federal da Bahia (UFBA), Universidade Federal de Sergipe (UFS) e Universidade de M inas Gerais (UFM G). Após esta experiência inicial, o M inistério da Educação (M EC) lançou, em 2008, o primeiro edital convocando as IES públicas do País para submeter projetos de graduação em Licenciatura em Educação do Campo (TAFFAREL; SANTOSJÚNIOR, 2011).

No Estado do Amapá, nos anos de 2008 e 2009, o Procampo apoiou projetos na área de Ciências Naturais - Licenciatura em Educação do Campo com Docência multidisciplinar em Física e Biologia. Os cursos foram executados nos campi da UNIFAP nos municípios de Laranjal do Jarí e Mazagão, formando duas turmas de licenciados para as escolas do campo do Estado do Amapá.

Em seu conjunto, o artigo problematiza a implantação dos cursos do Procampo na UNIFAP, a participação dos movimentos sociais amapaenses nesse processo e aponta os entraves e dificuldades na execução do programa nos campi dos municípios de Laranjal do Jari e Mazagão. Para situar a dimensão histórico-social da educação, 0 texto aponta os aspectos teóricos e conceituais considerados centrais para entender a Educação do Campo. Em seguida são apresentados os dados da pesquisa de campo que foram obtidos nos questionários e entrevistas que exploraram a materialização do programa no âmbito da UNIFAP, buscando-se compreender os agentes, os sujeitos e as instâncias deste processo por meio dos discursos expositivos. Por fim, são apresentadas algumas considerações sobre a importância dos cursos de LEDOC como fenômeno educacional específico que contribuiu para a formação do docente do campo no contexto amapaense. 


\section{EDUCAÇÃO DO CAMPO E FORMAÇÃO INICIAL DE PROFESSORES: 0 PROCAMPO NO AMAPÁ - ASPECTOS HISTÓRICOSE CONCEITUAIS}

As políticas públicas para a Educação do Campo são entendidas dentro do contexto de mudanças ocorridas nos anos 1990 , oriundas da política neoliberal de minimização do papel do Estado que afetou o cenário político, econômico e social mundial e do Brasil. Como reflexo dessas transformações, a educação foi envolvida por estratégias e reformas orientadas por interesses de reorganização do capital financeiro.

Nesse contexto, houve o fortalecimento dos movimentos sociais do campo que reivindicavam a Reforma Agrária e, igualmente, os direitos sociais para as populações do campo. Sobre a efervescência dos movimentos sociais, Delgado (2005), diz que este fenômeno ocorreu em virtude do ajustamento do Estado brasileiro à ordem da economia globalizada e o avanço do agronegócio que ganhou centralidade nas políticas do governo, prejudicando o pequeno produtor e o agricultor familiar.

A proposta de uma educação diferenciada para a população camponesa foi suscitada no setor de educação do M ovimento dos Trabalhadores Rurais Sem Terra (MST) e ganhou o âmbito nacional, contando com o apoio e a colaboração de outros movimentos sociais. Conforme afirma Paladim Júnior (2010, p. 56), a "educação para 0 MST é uma preocupação mais ampla do que a luta por escolas dentro de acampamentos e assentamentos". Nesse sentido, a educação é pensada como base no processo de desenvolvimento socioterritorial das lutas camponesas no Brasil.

Ainda na década de 1990 nasceu o movimento Por uma Educação do Campo, com a finalidade de discutir, propor políticas e assegurar os direitos educativos dos sujeitos do campo. Como afirma Vendramini (2007, p. 123):

É preciso compreender que a educação do campo não emerge no vazio e nem é iniciativa das políticas públicas, mas emerge de um movimento social, da mobilização dos trabalhadores do campo, da luta social. É fruto da organização coletiva dos trabalhadores diante do desemprego, da precarização do trabalho e da ausência de condições materiais de sobrevivência para todos.

A partir das demandas dos movimentos sociais surgiram as críticas às políticas educacionais gestadas fora da realidade campesina. Diante disso, foi necessário buscar referência para a construção do Paradigma de Educação do Campo, o que ficou registrado na I Conferência Nacional de Educação do Campo (I CNEC), em 1998, e posteriormente reafirmado na II CNEC, realizada no ano de 2004. Sobre a I CNEC, Souza (2006, p. 34) observa que: "nesta conferência, uma rede de movimentos, organizações, associações e organismos internacionais deram impulso ao debate sobre a educação básica do campo, suscitando o pensar sobre as políticas de educação".

Dentre as organizações envolvidas na Conferência de 1998 estiveram o MST, o M ovimento dos Atingidos por Barragens (M AB), o M ovimento das M ulheres Camponesas 
(M M C), o M ovimento dos Pequenos Agricultores (MPA) e a Comissão Pastoral da Terra (CPT). Na Conferência de 2004, foram incorporados os Sindicatos de Trabalhadores Rurais e as federações estaduais vinculados à Confederação Nacional dos Trabalhadores da Agricultura (CONTAG) e as organizações vinculadas à Rede de Educação do SemiÁrido Brasileiro (RESAB) (BRASIL, 2004). Na avaliação de Caldart (2004, p. 13), a I e a II CNEC representaram o "[...] momento de batismo coletivo de um novo jeito de lutar e de pensar a educação para o povo brasileiro que trabalha e vive no e do campo".

Diante disso, Caldart (2010, p. 105) afirma que a Educação do Campo "[...] é fruto da prática coletiva que, ao denunciar, exercita a participação coletiva e efetiva das categorias que são fundantes da política pública orientada para a transformação social". Da articulação dos movimentos sociais, importantes conquistas foram alcançadas como garantia de promoção da Educação do Campo. Dentre esses avanços podese ressaltar a aprovação das Diretrizes Operacionais para a Educação Básica nas Escolas do Campo (DOEBEC) - Resolução no. 01/2002/M EC/CNE, resultado das reivindicações do movimento Por uma Educação do Campo. De acordo com o Parecer no. $36 / 2001$, que criou as diretrizes mencionadas:

[...] os movimentos sociais do campo propugnam por algo que ainda não teve lugar, em seu estado pleno, porque perfeito no nível das suas aspirações. Propõem mudanças na ordem vigente, tornando visível, por meio das reivindicações do cotidiano, a crítica ao instituído e o horizonte da educação escolar inclusiva (BRASIL, 2002a, p. 09).

A carência de políticas públicas para atender os povos do campo está entre os fatores que impulsionaram os movimentos sociais na luta para assegurar 0 acesso aos bens públicos por meio de mecanismos legais. Sobre essa questão Costa (2016, p. 119) diz que "ao mesmo tempo em que há o discurso oficial e legal da política educacional, ainda permanece um cenário de exclusão das populações do campo no Brasil, o que reflete na baixa escolaridade e na dificuldade de efetivação dessa política". Nesse processo, revela-se a exclusão dos trabalhadores do campo do direito à educação, uma vez que a falta de investimento nas escolas e na formação dos professores é apontada como um dos elementos que contribuem para a baixa qualidade do ensino nas escolas do campo brasileiras.

A política pública específica para a formação inicial dos educadores das escolas do campo no ensino superior é ainda recente, compreendida pelos movimentos sociais como uma prática de fortalecimento da educação que tem entre suas bases legais o Decreto no 7.352/2010, que estabelece:

Art. 5․ A formação de professores para a educação do campo observará os princípios e objetivos da Política Nacional de Formação de Profissionais do Magistério da Educação Básica, conforme disposto no HYPERLINK "http://www.planalto.gov.br/ccivil_03/_ato2007-

2010/2009/Decreto/D6755.htm"Decreto $n^{0}$ 6.755, de 29 de janeiro de 
2009, e será orientada, no que couber, pelas diretrizes estabelecidas pelo Conselho Nacional de Educação.

$\S 1^{0}$ Poderão ser adotadas metodologias de educação à distância para garantir a adequada formação de profissionais para a educação do campo.

$\S 2^{\circ}$ A formação de professores poderá ser feita concomitantemente à atuação profissional, de acordo com metodologias adequadas, inclusive a pedagogia da alternância ${ }^{1}$, e sem prejuízo de outras que atendam às especificidades da educação do campo, e por meio de atividades de ensino, pesquisa e extensão.

$\S 3^{0}$ As instituições públicas de ensino superior deverão incorporar nos projetos político-pedagógicos de seus cursos de licenciatura os processos de interação entre o campo e a cidade e a organização dos espaços e tempos da formação, em consonância com as diretrizes estabelecidas pelo Conselho Nacional de Educação. (BRASIL, 2010).

Este Decreto, dispõe sobre a política de educação do campo e da necessidade de formação específica para os professores. A materialização dessa formação iniciou com a implementação dos cursos de LEDOC apoiados pelo Procampo.

O Procampo é uma política educacional de Estado legitimada pelo MEC no ano de 2008, através da Secretaria de Educação Continuada, Alfabetização, Diversidade e Inclusão (SECADI) com a colaboração da Secretaria de Educação Superior (SESU) e 0 Fundo Nacional de Desenvolvimento da Educação (FNDE). 0 referido programa teve como objetivo apoiar a implantação de cursos de Licenciaturas em Educação do Campo nas instituições públicas de ensino superior (IES) do País (BRASIL, 2009).

$\mathrm{Na}$ Lei de Diretrizes e Bases da Educação Nacional (LDBEN) no. 9.394/96, a formação dos profissionais da educação é definida em seu Art. 62, em que estabelece:

A formação do docente para atuar na educação básica far-se-á em nível superior, em curso de licenciatura, de graduação plena, em universidades e institutos superiores de educação, admitida, como formação mínima para o exercício do magistério na educação infantil e nos cinco primeiros anos do ensino fundamental, a oferecida em nível médio, na modalidade normal (BRASIL, 1996, 35).

Tomando como base a LDBEN vigente e as DOEBEC, a proposta do Procampo foi elaborada para que "[...] respondesse às necessidades de fortalecimento e ampliação da oferta da Educação Básica no campo" (ANTUNES- ROCHA, 2009, p. 41). Diante disso, os cursos de LEDOC/ Procampo são respaldados pelo Parecer CNE/CP №. 09/2001 e a Resolução CNE/CP №. 1/2002, que instituem as Diretrizes Curriculares Nacionais para a Formação de Professores da Educação Básica, em nível superior, curso de licenciatura,

\footnotetext{
${ }^{1}$ Alternância Pedagógica é uma metodologia de ensino-aprendizagem que pode ser desenvolvida em experiências de Educação do Campo. Hoje, a Pedagogia da Alternância passa a ser a principal referência para se identificar qualquer experiência de Educação do Campo, como o próprio nome já diz, alternam-se os dias família e propriedade e os dias escola e aprendizado (CAM ACHO, 2014, p. 392).
}

PRACS: Revista Eletrônica de Humanidades do Curso de Ciências Sociais da UNIFAP 
de graduação plena. 0 despreparo dos professores é apontado no Parecer CNE/CP №. 09/2001 como um dos fatores que dificultam o avanço da educação básica no País, portanto, ele "[...] apresenta a base comum de formação docente expressa em diretrizes, que possibilitem a revisão criativa dos modelos hoje em vigor" (BRASIL, 2001, p. 4).

O Parecer CNE/CP №. 28 de 2 de outubro de 2001 e a Resolução CNE/CEB №. 2, de 19 de fevereiro de 2002, definem o período de duração e a carga horária dos cursos de formação de professores da educação básica, em nível superior, licenciatura plena. Nesses documentos legais há a definição de espaço e tempo na formação docente, pois:

A carga horária dos cursos de Formação de Professores da Educação Básica, em nível superior, em curso de licenciatura, de graduação plena, será efetivada mediante a integralização de, no mínimo, 2.800 (duas mil e oitocentas) horas, nas quais a articulação teoria-prática garanta, nos termos dos seus projetos pedagógicos (BRASIL, 2002b, p. 1).

Outras legislações que amparam as Licenciaturas em Educação do Campo são o Parecer CNE/CEB №. 36/2001 e a Resolução CNE/CEB №. 1/2002, que Institui as DOEBEC; Resolução CNE/CEB №. 2, de 28 de abril de 2008, que instituiu as Diretrizes Complementares, Normas e Princípios para o Desenvolvimento de Políticas Públicas de Atendimento da Educação Básica do Campo; Parecer CNE/CEB №. 1/2006, que estabelece os dias letivos para a aplicação da Pedagogia de Alternância nos Centros Familiares de Formação por Alternância (CEFFA); Decreto №. 7.352, de 04 de novembro de 2010, que dispõe sobre a Política de Educação do Campo e o Programa Nacional de Educação na Reforma Agrária - PRONERA (TAFFAREL; SANTOS JÚNIOR, 2011).

Diante das diretrizes legais apresentadas, o Procampo insere-se em um processo de luta permanente de valorização do magistério, com sólida formação acadêmica dos professores das escolas do campo. Nesse sentido, os cursos de LEDOC procuram romper com o modelo de formação que fragmenta o conhecimento, uma vez que "o formato legal e institucional das licenciaturas existentes no sistema educacional é expressão de uma concepção de formação de educadores e de escola que diverge dos debates originários da Educação do Campo" (CALDART, 2011, p. 100).

Nesse sentido, a proposta do Procampo foi desenvolver licenciaturas multidisciplinares para formar os profissionais das escolas do campo. Para isso, os cursos foram organizados em regime de Alternância Pedagógica, intercalando o Tempo Universidade (TU) voltado para o campo teórico no ambiente universitário e o Tempo Comunidade (TC) utilizado para executar atividades práticas nas comunidades rurais. Além disso, os cursos foram organizados em áreas do conhecimento, conforme argumento de Antunes-Rocha (2009, p. 41):

A formação por área poderia ser um caminho para garantir o funcionamento de salas de segundo segmento do ensino fundamental e ensino médio no campo, constituindo-se assim como alternativa em um cenário em que a 
nucleação e o transporte dos alunos para escolas distante de suas residências têm sido as únicas possibilidades para a escolarização da educação do campo.

Nesse caso, a qualificação dos professores por áreas do conhecimento possibilita uma experiência diferenciada, específica que visa superar o paradigma de formação que transforma o profissional em "[...] protótipo, único, genérico de docenteeducador para a educação básica" (ARROYO, 2012, p. 361). Dessa forma, busca-se, por meio da interdisciplinaridade, a articulação com a realidade camponesa, com as relações sócio-históricas, políticas e culturais dos trabalhadores do campo (M OLINA, 2014).

Com a chamada pública lançada pelo M EC, em 2008, a UNIFAP apresentou proposta da LEDOC-Docência multidisciplinar em Física e Biologia, que foi aprovada e implantada no campus da instituição no M unicípio de Laranjal do Jarí2. 0 projeto do referido curso foi conduzido pelo "edital de Convocação no 02, de 23 de abril de 2008SECADI/MEC" (UNIFAP, 2011, p. 21). Em 2009, a UNIFAP conseguiu a aprovação de seu segundo projeto de LEDOC-Docência multidisciplinar em Física e Biologia, conduzido pelo "edital de convocação no 09, de 29 de abril de 2009" (BRASIL, 2009), ofertado no campus da universidade no M unicípio de M azagão ${ }^{3}$.

De acordo com o Projeto Político do Curso (PPC), a LEDOC/Procampo seguiu as diretrizes e princípios da Educação do Campo, uma vez que:

O Projeto "Licenciatura em Educação no Campo" da UNIFAP objetiva realizar um curso em que a formação é mediada pela produção do conhecimento ancorado/mobilizado na experiência de vida do professor e de sua identidade, construindo-se a partir da compreensão de uma prática interativa e dialógica entre o indivíduo e o coletivo relacionada à "rede de ciência e tecnologia disponível na sociedade e nos movimentos sociais em defesa de projetos que associem as soluções exigidas por essas questões da qualidade social de vida coletiva no país" (UNIFAP, 2011, p. 9).

0 ingresso nos cursos de LEDOC foi realizado através de processo seletivo definido por meio de editais específicos organizados pela UNIFAP, que estabeleceu a oferta de 60 vagas destinadas aos campi do Laranjal do Jari e 60 para o M azagão.

Os campi da UNIFAP em Laranjal do Jari e no Mazagão reuniram professores de escolas do campo de vários municípios do Estado do Amapá para cursar a Licenciatura em Educação do campo, conforme é demonstrado no mapa 1.

${ }^{2}$ O M unicípio de Laranjal do Jarí possui uma área de 31.170 km2, localizado cerca de 276 km da capital, Macapá. Localiza-se na região sudoeste do Estado do Amapá à margem esquerda do Rio Jari, Com uma população estimada em 2014 de 44.777 habitantes é o terceiro município amapaense mais populoso (IBGE, 2014).

${ }^{3} \mathrm{O}$ M unicípio de Mazagão localiza-se ao sul do Estado do Amapá, compreendendo uma área é de 13, 131 km². Estima-se que tenha uma população estimada de 19.157 habitantes em 2014 (IBGE, 2014). 
Mapa 1 - Mapa de localização dos egressos do Procampo UNIFAP, campus de Laranjal do Jari.

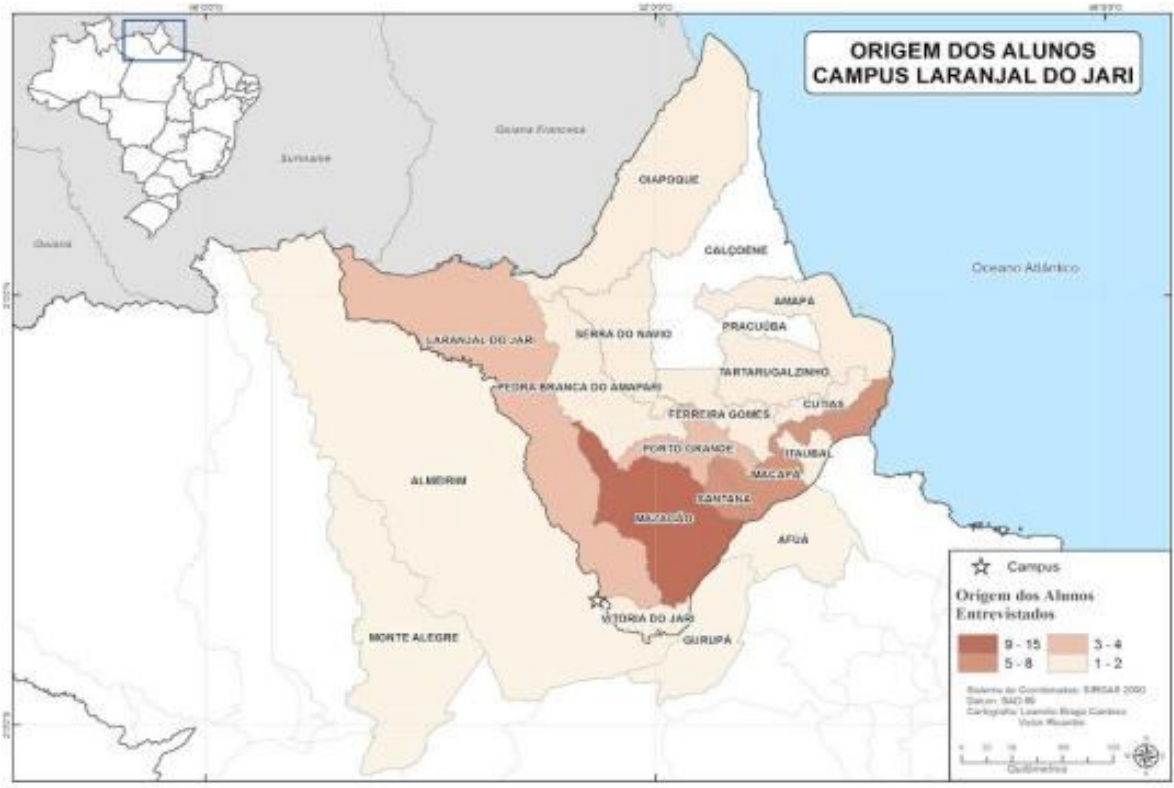

Fonte: Elaborado por Costa (2016).

De acordo com o PPC, a elaboração dos cursos do Procampo contou com a participação dos movimentos sociais e secretarias de educação, com isso, "as vagas também podem ser preenchidas através de seleção, realizada pelas Secretarias Municipais de Educação, com a indicação de educadores do campo, da rede de ensino, que não possuam curso de graduação (UNIFAP, 2011, p. 15).

Sendo assim, o Procampo possibilitou ampliar o debate sobre a realidade das escolas do campo e da formação dos seus profissionais no Estado do Amapá. Com o referido programa, a LEDOC passou a configurar como uma política pública permanente em 42 IES públicas do País, inclusive na UNIFAP.

De acordo com os dados levantados nos documentos oficiais do Procampo no Estado do Amapá e das entrevistas realizadas com os egressos, a turma de LEDOC campus do Laranjal do Jari reuniu docentes de escolas do campo das seguintes localidades: Macapá, Mazagão, Santana, Ferreira Gomes, Porto Grande, Laranjal do Jari, Tartarugalzinho, Oiapoque, Tumucumaque, Serra do Navio, Cutias, Amapá, Itaubal do Piririm, Pedra Branca do Amaparí, Vitoria do Jari, Almeirim (Estado do Pará), Gurupá (Estado do Pará), Afuá (Estado do Pará), M onte Alegre (Estado do Pará).

Da mesma forma, o campus da UNIFAP no município do Mazagão concentrou acadêmicos de diferentes localidades do Estado do Amapá e do Pará, como pode ser observado no mapa 2. 
Mapa 2 - Mapa de localização dos egressos do Procampo UNIFAP, campus do M azagão.

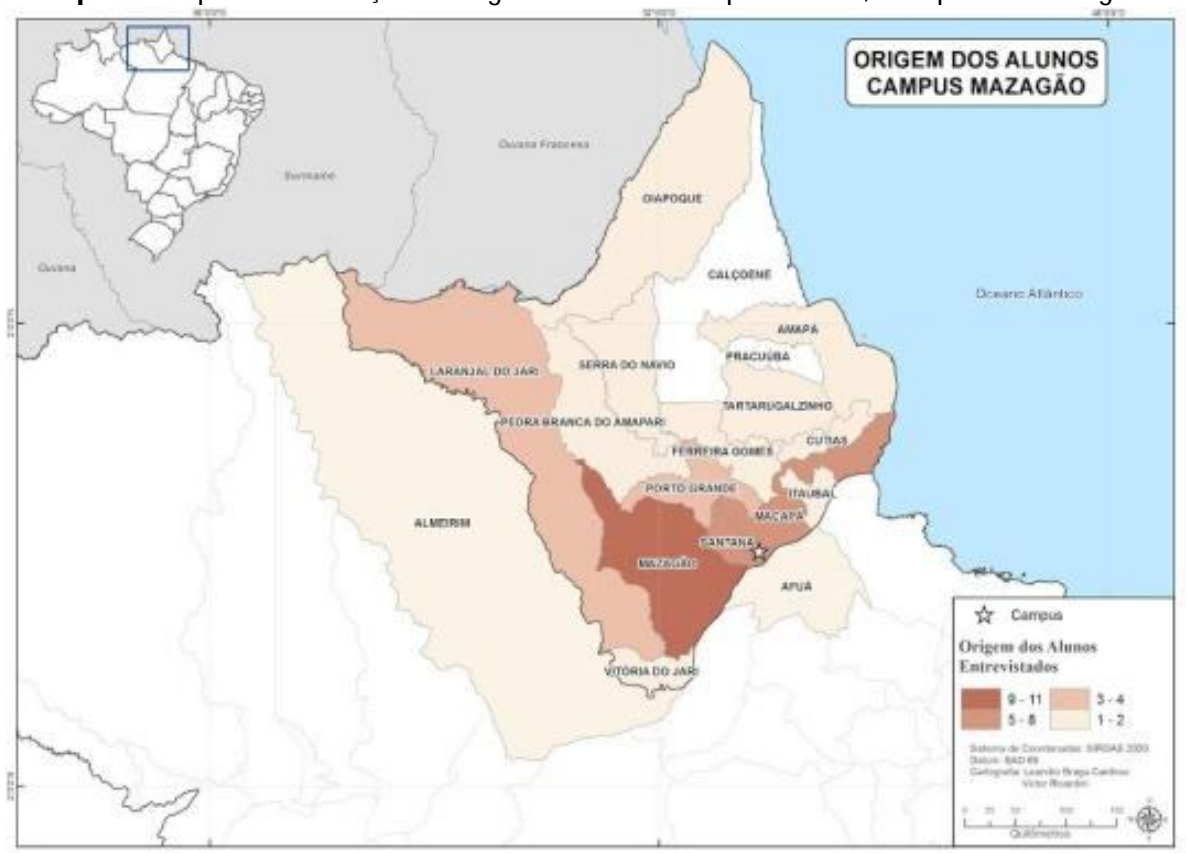

Fonte: Elaborado por Costa (2016).

Na turma de LEDOC/Procampo ofertado no campus do Mazagão houve a participação de professores/acadêmicos das escolas do campo de diferentes municípios e comunidades como: Macapá, Mazagão, Santana, Ferreira Gomes, Porto Grande, Laranjal do Jari, Tartarugalzinho, Oiapoque, Tumucumaque, Serra do Navio, Cutias, Amapá, Itaubal do Piririm, Pedra Branca do Amaparí, Vitoria do Jari, Almeirim (PA), Afuá (PA).

O desenvolvimento da LEDOC/Procampo nos campi do interior do Estado do Amapá proporcionou a formação inicial de profissionais que atuam na educação do campo em vários municípios amapaenses e paraenses. Nessa perspectiva, verifica-se a importância desses cursos para atender a demanda de formação dos trabalhadores do campo. A organização dos cursos nos campi do Laranjal do Jari e do Mazagão proporcionou a concretização de uma iniciativa que viabilizou espaços-tempos de diálogo entre a academia e a realidade das comunidades rurais, por meio da Pedagogia da Alternância.

\section{A LICENCIATURA EM EDUCAÇÃO DO CAMPO NO AMAPÁ: A FORMAÇÃO DO EDU- CADOR FRENTE AOS DESAFIOS AMAZÔNICOS}

Com a aprovação da LDBEN №. 9.394/96 e a definição dos critérios para a formação inicial dos profissionais da educação básica foi estipulado, pelo MEC, o prazo de uma década, a contar de 1996 a 2006, para que os docentes das escolas públicas pudessem obter a formação em nível superior. Após a "Década da Educação" ${ }^{4}$, apenas

\footnotetext{
${ }^{4}$ Período instituído com a aprovação da LDB 9.394/96 para a formação dos professores da Educação Básica. Conforme Art. 87. É instituída a "Década da Educação", período estipulado pelo MEC para que todos os pro-
} 
os professores licenciados deveriam permanecer em sala de aula ou participar de concurso público para lecionar na educação básica.

No entanto, o censo escolar de 2012 apontou que nesse período havia 2.101.408 docentes atuando na educação básica e $22 \%$ destes não possuíam formação adequada. Neste percentual estavam inclusos os professores sem nível superior e aqueles formados em áreas que não correspondiam a cursos de licenciatura (INEP, 2012). Diante dessa realidade, Gatti $(2014$, p. 32) afirma que em 2013:

[...] apenas parte dos professores que estavam atuando nas redes de ensino nos anos finais do ensino fundamental e ensino médio possuía formação na disciplina que lecionavam. Em Português, apenas 54,0\% tinham essa formação (sendo a proporção mais alta encontrada), em Matemática, somente $38,6 \%$ atendiam a essa condição, em Física, apenas 16,9\% (a proporção mais baixa).

Em 2015, os dados sobre a formação docente por região apontavam significativa disparidade entre o Norte e Nordeste, que apresentam um percentual menor de professores com qualificação adequada atuando em todos os níveis da educação básica em relação às demais regiões brasileiras (INEP, 2015). Nesse sentido, a narrativa do egresso do Procampo corrobora com essa informação quando reporta-se à sua experiência em escola do campo no Amapá:

[...] por eu ter estudado em escola pública enfrentei dificuldades muito grandes, inclusive, eu fui aluno da zona rural, estudei de $1^{1}$ a a $4^{a}$ série na zona rural mesmo, a gente tinha que pegar canoa para chegar na escola, tínhamos professores que não tinham formação, como dizem eram professores leigos, professores que tinham só até a 4a série do ensino fundamental, outros que tinham até a 8 a série que trabalhavam nessa época na zona rural, então, eles não tinham conhecimento suficiente para repassar pra gente e eu senti muita dificuldade quando cheguei na 5 a série, eu cheguei até a ficar reprovado na $5 \underline{a}$ série por causa dessa deficiência que é muito grande de conteúdos que eu trouxe de lá da zona rural e quando eu entrei na universidade não foi diferente, eu senti muitas dificuldades pelo fato de eu ter tido uma educação muito precária no ensino fundamental e médio (Informação verbal, M azagão, 2015).

Para uma compreensão mais ampla da realidade da Educação do Campo no Estado do Amapá, os dados consolidados sobre as matrículas na educação básica revelam que no ano de 2015 foram matriculados 39.615 alunos nas escolas do campo, como está demonstrado no quadro abaixo:

fessores da Educação Básica tivessem formação em nível superior (BRASIL, 2013, p. 44).

PRACS: Revista Eletrônica de Humanidades do Curso de Ciências Sociais da UNIFAP 
Quadro 1 - M atrícula inicial por etapa de ensino, no Estado do Amapá - 2015.

\begin{tabular}{|c|c|c|c|c|c|c|c|c|c|c|c|c|}
\hline \multirow[b]{2}{*}{ 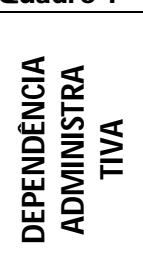 } & \multirow[b]{2}{*}{$\frac{\$}{8}$} & \multicolumn{3}{|c|}{ EDUCAÇÃOO INFANTIL } & \multicolumn{3}{|c|}{ ENSINO FUNDAMENTAL } & \multirow[b]{2}{*}{ 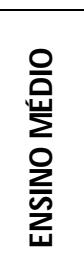 } & \multirow[b]{2}{*}{ 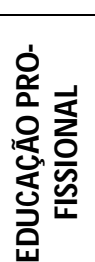 } & \multirow[b]{2}{*}{ 西 } & \multirow[b]{2}{*}{ 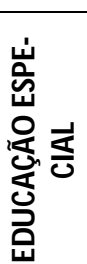 } & \multirow[b]{2}{*}{$\begin{array}{l}\frac{1}{2} \\
\frac{5}{2}\end{array}$} \\
\hline & & ș & $\begin{array}{l}\text { 岁 } \\
\text { 岁 } \\
8\end{array}$ & $\begin{array}{l}5 \\
8 \\
4 \\
4 \\
4\end{array}$ & $\frac{1}{\delta}$ & $\begin{array}{l}\frac{n}{z} \\
0 \\
\frac{2}{y} \\
\frac{z}{8}\end{array}$ & $\begin{array}{l}\frac{y}{3} \\
\frac{1}{15} \\
\frac{1}{8} \\
\frac{z}{z}\end{array}$ & & & & & \\
\hline Estadual & Rural & 283 & & 283 & 20251 & 10355 & 9896 & 3698 & - & 1942 & 3 & 26177 \\
\hline Municipal & Rural & 4125 & 337 & 3788 & 8193 & 7686 & 507 & - & - & 533 & 2 & 12853 \\
\hline Privada & Rural & - & - & - & 210 & - & 210 & 284 & 91 & - & - & 585 \\
\hline & & & & OTAL & $2 \mathrm{ALDEI}$ & ATRÍCUL & & & & & & 39.615 \\
\hline
\end{tabular}

Fonte: Elaboração por Costa (2016), com base nos dados do CEPE/SEED (2016).

De acordo com os dados apresentados no quadro acima, em 2015, a distribuição de matrículas nas escolas do campo apresentou significativas variações entre os níveis e as modalidades de ensino. 0 ensino fundamental concentrou o total de 20.251 alunos matriculados na rede pública, sendo que maioria encontra-se nos anos iniciais em que a demanda é maior e ocorre, principalmente, por meio da multisseriação.

Para atender esse quantitativo de 39.615 alunos distribuídos entre as redes públicas municipais, estadual e a esfera privada de ensino, o Estado do Amapá contava com um quadro de 3.422 professores atuando na educação básica nas escolas do campo, conforme disposto no quadro 2.

Quadro 2 - Docentes por etapa de atuação, no Estado do Amapá, 2015.

\begin{tabular}{|c|c|c|c|c|c|c|c|c|c|c|}
\hline \multirow{2}{*}{ 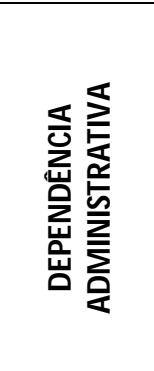 } & \multirow[b]{2}{*}{ ZONA } & \multirow{2}{*}{$\begin{array}{l}\text { E } \\
\mathbf{z} \\
\frac{1}{2} \\
\frac{8}{8} \\
8 \\
8 \\
8 \\
8\end{array}$} & \multicolumn{2}{|c|}{$\begin{array}{c}\text { ENSINO } \\
\text { FUNDAMENTAL }\end{array}$} & \multirow[b]{2}{*}{ 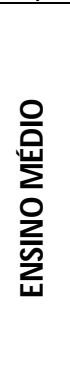 } & \multicolumn{2}{|c|}{ EJA } & \multirow{2}{*}{$\begin{array}{l}\frac{1}{8} \\
8 \\
\frac{8}{4} \\
8 \\
8 \\
8 \\
8 \\
8 \\
8 \\
0\end{array}$} & \multirow{2}{*}{ 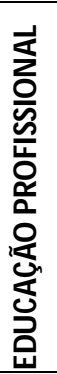 } & \multirow{2}{*}{$\begin{array}{l}\text { 昌 } \\
8 \\
8 \\
8 \\
\text { 岁 } \\
\text { 岁 }\end{array}$} \\
\hline & & & $\begin{array}{l}\frac{n}{8} \\
\frac{2}{2} \\
\frac{2}{8} \\
\frac{8}{8}\end{array}$ & $\begin{array}{l}\frac{n}{8} \\
\frac{2}{1} \\
\frac{1}{8} \\
\frac{8}{8}\end{array}$ & & 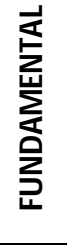 & 号 & & & \\
\hline Estadual & Rural & 36 & 758 & 769 & 351 & 250 & 40 & 11 & 10 & 2.288 \\
\hline M unicipal & Rural & 293 & 342 & 37 & - & 72 & - & 1 & - & 1.073 \\
\hline Privada & Rural & - & - & 40 & 49 & - & - & - & 9 & 61 \\
\hline \multicolumn{10}{|c|}{ Total Geral de Docentes } & 3.422 \\
\hline
\end{tabular}

Fonte: Elaboração por Costa (2016) com base nos dados do CEPE/ SEED (2016).

Assim como ocorreu com as matrículas, o ensino fundamental foi o nível que concentrou o maior quantitativo de professores nas escolas do campo, sendo o total de 1.946 profissionais. No Estado do Amapá, muitos desses docentes encontram-se lotados em turmas multisseriadas, principalmente, nas comunidades rurais em que as matrículas nos anos iniciais do ensino fundamental são, relativamente, baixas e assim eles acumulam outras funções como gestão administrativa e pedagógica das escolas.

$\mathrm{Na}$ análise sobre os egressos da LEDOC/Procampo, pôde-se constatar que $86 \%$ deles trabalhavam nos anos iniciais do ensino fundamental, lecionando para mais de uma série/ano e disciplina, ou seja, estavam inseridos nas classes de multisseriação 
(UNIFAP, 2011). Para a Secadi (BRASIL, 2007, p. 22):

[...] o problema das turmas multisseriadas está na ausência de uma capacitação específica dos professores envolvidos, na falta de material pedagógico adequado e, principalmente, a ausência de infra-estrutura básicamaterial e de recursos humanos-que favoreça a atividade docente e garanta a efetividade do processo de ensino-aprendizagem.

Outra questão relevante sobre a Educação do Campo no Estado do Amapá é a baixa oferta do ensino médio nas comunidades rurais, impossibilitando a continuidade de escolarização da população. Além disso, o ensino médio é ofertado por meio do sistema modular ${ }^{5}$, uma vez que há carência de docentes dos diferentes componentes curriculares que integrem o quadro efetivo nas escolas do campo e devido às longas distâncias que os educandos têm que enfrentar para chegar às escolas, muitos abandonam as salas de aulas e, portanto, não chegam a concluir este nível de ensino.

Especificamente, sobre os egressos do Procampo do campus da UNIFAP no município de Mazagão, 89\% deles não residiam na comunidade em que trabalhavam. Um dos problemas enfrentados pelas escolas do campo no Amapá é a falta de vínculo do professor com a comunidade, pois a maioria dos professores egressos das turmas do Procampo não reside em comunidade do campo, são profissionais que passam apenas os períodos letivos nas comunidades. Um agravante desse processo é que as escolas são afetadas pela alta rotatividade dos professores, deixando, muitas vezes, os educandos por períodos prolongados sem aula, prejudicando a qualidade do ensino, o que recai sobre a aprendizagem, ocasionando a má qualidade e os baixos níveis de escolarização da população.

Nesse sentido, Ferreira (2006, p. 10) discute que para assumir cargo em regiões longínquas, muitos docentes são obrigados a conviver com inúmeras dificuldades, pois muitas escolas não possuem "[...] nenhuma infraestrutura para a realização do trabalho docente ou para a sua própria vida pessoal. [...] sem perspectivas, muitos professores tentam se remover para escolas com mais condições, de preferência na capital".

Essa afirmação traduz a realidade de muitas escolas do campo no Estado do Amapá, pois há comunidades rurais afastadas dos núcleos urbanos que apresentam dificuldade de acesso, principalmente, pela via terrestre. Entretanto, os professores que residem e desempenham suas atividades pedagógicas no campo entendem os desafios a serem enfrentados diariamente, seja por questões relativas à falta de estrutura física ou de permanência dos educandos, como fica evidente na fala do egresso:

O professor da escola do campo no Amapá tem que ser um guerreiro, tem

\footnotetext{
${ }^{5}$ Sistema M odular de Ensino - Forma de organização dos docentes para que passem um curto período de tempo em uma comunidade do campo para ministrar uma disciplina específica e, logo após deslocam-se para outras comunidades a fim de atender a demanda de outras escolas (Costa, 2016).
} 
que enfrentar as dificuldades que não são poucas, a começar pelos prédios das escolas que são precários, isso quando tem prédios, porque em muitos casos as aulas acontecem na sala da casa de alguém da comunidade que cede para funcionar a escola ou quando tem o prédio da escola do município é precário. Não temos energia elétrica, eu acredito que na zona rural do município do Mazagão, a escola enfrenta inúmeras dificuldades pelo fato de não ter material didático, não ter merenda e quando tem é de péssima qualidade e toda aquela questão do transtorno de passar 8, 10 e até mesmo 15 horas dentro de um catraio pequeno para se deslocar daqui da sede do município até chegar nas escolas do campo que são bastante distantes e nós temos que enfrentar maresia, chuva e sol em catraios ${ }^{6}$ que não tem conforto nenhum e vários outras situações que a gente se depara no dia a dia na zona rural (Informação verbal, 2015, M azagão).

Nesse depoimento, as dificuldades para o exercício da prática educativa nas escolas do campo aparecem como expressões do cotidiano dos professores. As narrativas estão entrelaçadas pela vida pessoal, social e profissional.

Concernente às questões pedagógicas, um egresso do Procampo diz que:

Ser um educador do campo no estado do Amapá é uma coisa mirabolante, porque todos os livros e materiais didáticos que vêm para a escola, não são voltados para o nosso meio. Eu já passei por situação da criança me perguntar o que é um bairro, porque tem uma definição no livro do que é um bairro e ele me dizer, mas professora eu não sei o que é um bairro porque no campo não tem bairro, além de outras coisas, por exemplo, se fala muito da cidade e aí a criança vive no campo e fica, totalmente, perdida (Informação verbal, 2015, M azagão).

Em um contexto marcado pela baixa escolaridade dos sujeitos, a elaboração de material didático inadequado para atender os estudantes implica no reconhecimento de que ainda há muito a avançar nas políticas de Educação do Campo. Como se pode analisar na declaração do egresso do Procampo, além da dificuldade de acesso e das más condições estruturais das escolas do campo, está a inadequação dos livros e materiais didáticos que não são condizentes com a realidade dos educandos, reafirmando um ensino descontextualizado, em que há apenas uma transposição do currículo urbano para o campo. Esse cenário narrado pelo entrevistado é discutido por Reis (2011, p. 114) que diz "se buscarmos levantar ao longo da história da educação brasileira, iremos facilmente identificar o descaso com que sempre foi tratada e pensada a educação voltada para a população e educadores do campo".

A LDBEN vigente, em seu Art. 4을 inciso VII, faz referência ao programa de apoio ao ensino fundamental por meio de "[...] programas suplementares de material didático

${ }^{6}$ Catraio é um tipo de embarcação de pequeno porte muito comum nos rios da Amazônia, utilizado pelos ribeirinhos para transportar pessoas e na pesca artesanal (DICIONÁRIO PRIBERAM DA LíNGUA PORTUGUESA, 2013). 
[...]" (BRASIL, 2013, p. 3), cuja finalidade é garantir o atendimento aos educandos da rede pública de ensino. No entanto, a política educacional brasileira desconsidera as necessidades didático-pedagógicas dos sujeitos do campo. Corroborando com Arroyo (2007, p. 159), essas políticas vão “[...] adaptando às condições do campo a educação escolar, os currículos e a formação dos profissionais pensados no paradigma urbano".

Diante das informações pontuadas na fala do egresso, há de se considerar que "a realidade destes sujeitos não costuma ser considerada quando se projeta um desenho de escola" (CALDART, 2007, p. 4) e essas questões transcorrem a história da educação dos povos do campo no sentido de que esta representa apenas um ônus financeiro e a relação custo-benefício é insignificante para o Estado e isto pode ser observado na análise de documentos de períodos anteriores aos anos 1990, em que as políticas educacionais para o campo eram, praticamente, inexistentes.

Diante desse descaso com a educação dos trabalhadores do campo, para elaborar a proposta do Procampo levou-se em consideração a carência de docentes para lecionar nos anos finais do ensino fundamental e no ensino médio. Na UNIFAP, os cursos do Procampo priorizaram as áreas de Ciências da Natureza com ênfase à docência em física e biologia, uma vez que, no Amapá, há carência de professores dessas disciplinas, sendo que para atender as escolas do campo esta situação é ainda mais grave, pois os profissionais formados nessas áreas do conhecimento estão, em sua maioria, lotados nas escolas urbanas.

Para Caldart (2011, p. 79), a formação por área do conhecimento é:

[... ] apenas uma das ferramentas escolhidas (considerando as circunstâncias históricas determinadas) para desenvolver uma das dimensões (a docência) do projeto de formação de educadores que dê conta de pensar o caminho de transformação da escola desde o acúmulo de reflexões já existentes sobre isso no âmbito da educação do campo e, especialmente, dos movimentos sociais camponeses.

0 aprimoramento do professor é primordial para avançar na qualidade do ensino. Pensar a melhoria da educação do campo é, também, buscar na formação do docente a estratégia para essa mudança, uma vez que "toda formação encerra um projeto de ação e de transformação" (NÓVOA, 1992, p. 31). Nesse sentido, a educação é considerada um elemento importante de transformação social.

Entende-se que os conhecimentos teóricos apresentados na LEDOC/Procampo possibilitaram ao docente "compreender e explicar os processos educativos dos quais participa, como também para contribuir na transformação da realidade educacional no âmbito de seus projetos pessoais e coletivos" (RAM ALHO; NUÑEZ; GAUTHIER, 2004, p. 23), tomando suas experiências pedagógicas como ponto de partida.

Para cumprir com as diretrizes e princípios da educação do campo, a organização curricular e metodológica dos cursos LEDOC-Docência Multidisciplinar em Física e Biologia tiveram como base a Alternância Pedagógica e a formação por áreas do conheci- 
mento, pois favorece "[...] o desenvolvimento de propostas de trabalho interdisciplinar, na educação básica" (BRASIL, 2001, p.47), visando vencer a fragmentação do currículo e contribuir para que os professores consigam "[...] fazer permanentemente a transposição didática, isto é, a transformação dos objetos de conhecimento em objetos de ensino" (op. cit., 2001, p. 56).

Para garantir a alternância pedagógica no curso de LEDOC da UNIFAP foi organizado o Tempo Universidade (TU) e o Tempo Comunidade (TC) objetivando vincular a teoria com a prática por meio de tempos distintos para a formação. Conforme afirmação de Antunes-Rocha (2011, p. 154) "a formação tempo escola, alternada como 0 tempo comunidade, aponta para uma temporalidade articulada com a espacialidade".

Nesse sentido, o TU ocorreu nos campi da UNIFAP nos municípios de Laranjal do Jari e M azagão, com aulas presenciais desenvolvidas em tempo integral nos meses de janeiro e julho, conforme descrito no Projeto Pedagógico do Curso (PPC):

O Curso de Licenciatura em Educação do Campo funciona com tempo integral no período de férias e recesso escolar. E também com estudos realizados através da alternância pedagógica, que se materializa através dos Projetos Vivenciais, como uma estratégia de escolarização que possibilita aos acadêmicos que vivem e trabalham no campo conjugar a formação universitária sem desvincular-se do trabalho, da família e da cultura do campo (UNIFAP, 2011, p. 14).

O TU foi organizado no período das férias escolares dos professores do campo e veio responder à realidade do Estado do Amapá, uma vez que muitas comunidades estão localizadas afastadas da sede dos municípios e, portanto, apresentam dificuldade de acesso, como destacado pelo egresso do curso:

No meu caso há dificuldade de acesso, o transporte só é de barco, a gente depende de maré, tanto para o aluno chegar na escola, quanto para quem vem para Macapá, porque só se chega lá de barco, não tem outro transporte e precisa da maré para entrar e sair (Informação verbal, 2015, Laranjal do Jari).

O TC ocorreu nos meses intervalares ao TU. Nele, os acadêmicos do Procampo desenvolveram as atividades propostas no Projeto Vivencial ${ }^{7}$, buscando integrar a educação com a realidade das comunidades do campo. Para cumprir esses tempos da formação, o currículo da LEDOC da UNIFAP foi dividido em quatro núcleos que buscavam priorizar os objetivos e princípios preconizados na legislação e nas diretrizes de

\footnotetext{
${ }^{7} 0$ Projeto vivencial constitui atividade curricular formativa e contempla uma metodologia proposta que prioriza a "integração" em cada semestre para os cursos do PROCAM PO, objetivando um melhor entendimento e relação entre as disciplinas, com o objetivo de concretizar a alternância pedagógica através do tempo escola e tempo comunidade (UNIFAP, 2010, p. 19).
} 
referência da Educação do Campo. Na representação gráfica abaixo é possível observar a distribuição percentual da carga horária dentro de cada núcleo curricular da LEDOC:

Gráfico 2. Distribuição da carga horária do curso de PROCAM PO-UNIFAP.

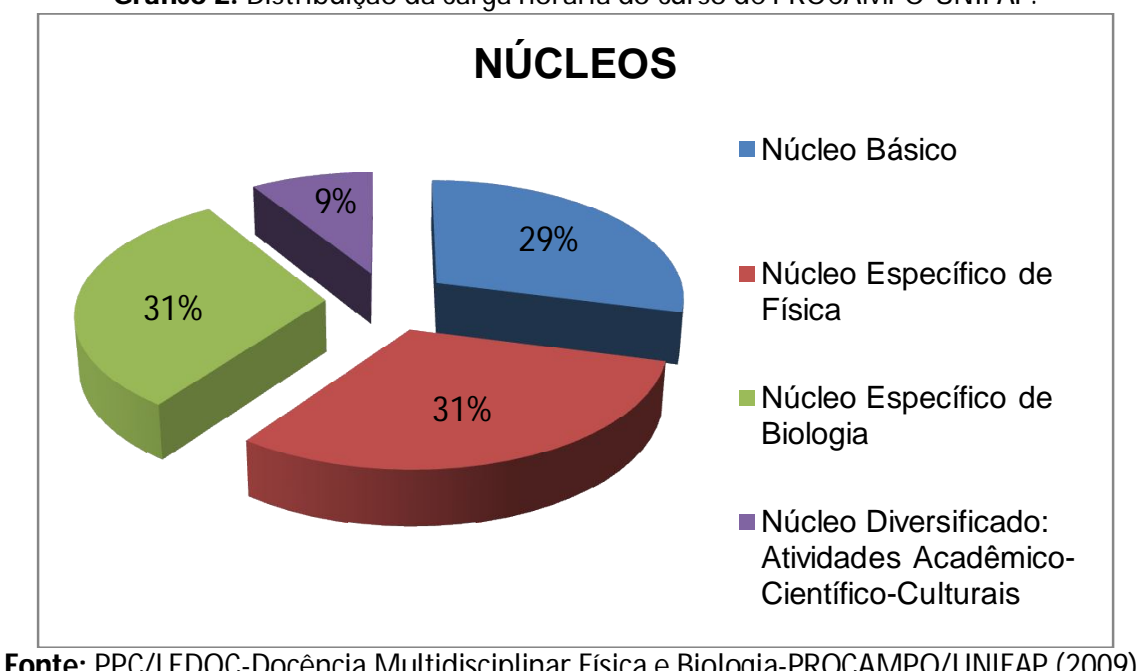

Nos cursos do Procampo foi efetivada uma carga total de $4.215 \mathrm{~h}$, sendo $1.230 \mathrm{~h}$ do núcleo básico (composto por 14 disciplinas); 1.290h do núcleo específico de física (com 08 disciplinas de física, 02 disciplinas práticas, mais 02 disciplinas de estágio supervisionado); $1.290 \mathrm{~h}$ do núcleo específico de biologia (abrangeu 08 disciplinas biológicas, mais 02 disciplinas práticas e 02 disciplinas de estágio supervisionado) e 405h do núcleo diversificado que compreende atividades complementares (participação em eventos, Projetos de Pesquisa e Extensão, dentre outros) (UNIFAP, 2010).

Entretanto, o cumprimento da matriz curricular da Educação do Campo na UNIFAP foi um desafio refletido nas dificuldades de acesso, comunicação, transporte, estrutura física dos campi da instituição no interior do estado, falta de recursos humanos e materiais para o desenvolvimento das aulas no TU. Além das questões pedagógicas como aulas exaustivas e condensadas, causando perdas à qualidade da formação. No trecho da entrevista de um dos docentes que lecionou nos cursos do Procampo fica evidente essa problemática:

Outra coisa que atrapalhou bastante esta formação foi termos que ministrar as disciplinas de forma condensada no período de férias, porque os professores chegavam cansados do período letivo nas escolas e nós tínhamos que ministrar uma disciplina de $60 \mathrm{~h}$ dentro de uma semana, uma de $120 \mathrm{~h}$ em duas semanas de manhã e a tarde. As disciplinas que eram agendadas para os últimos blocos, os alunos estavam totalmente esgotados (Informação verbal, 2015, M acapá).

A fala do professor revela o esforço inicial para a implantação da política de forma- 
ção dos profissionais das escolas do campo no Estado do Amapá. De acordo com a entrevista citada é possível perceber a preocupação dos docentes em relação ao TU, que foi organizado no período das férias escolares nas escolas do campo. Além disso, a falta de infraestrutura como biblioteca, laboratório de física e biologia para realização das aulas práticas foram indicadas como fatores que influenciaram na qualidade das aulas nos cursos.

Devido à ausência de estrutura laboratorial nos campi da UNIFAP para atender a formação do Procampo, as aulas práticas foram efetivadas no campus de Macapá, fora da realidade dos acadêmicos. Entende-se que a realização dessas atividades aliadas ao contexto campesino seria favorecedor para a troca de experiências e reflexões sobre a práxis pedagógica, pois "[...] a profissão de professor precisa combinar sistematicamente elementos teóricos com situações práticas reais" (LIBÂNEO; PIMENTA, 1999, p. 267).

Além disso, a formação multidisciplinar por áreas do conhecimento tem sido um desafio para muitos professores, pois há dificuldade de trabalhar o currículo com base na alternância pedagógica e na interdisciplinaridade, uma vez que estes elementos procuram integrar as disciplinas, criando uma interseção entre os saberes do TU e do TC, associando a teoria com a prática de maneira significativa nos cursos de formação em LEDOC.

A implantação e a execução dos cursos do Procampo no âmbito da UNIFAP apresentaram inúmeros obstáculos devido à falta de know-how da instituição na oferta de cursos específicos para atender os povos do campo e a formação em LEDOC é recente. A promoção da equidade, a garantia de acesso e permanência dos sujeitos do campo em todos os níveis da educação básica e no ensino superior postula a elaboração de políticas públicas adequadas à realidade camponesa.

\section{CONSIDERAÇÕES FINAIS}

A partir da década de 1970, o Brasil vem experimentando importantes transformações na estrutura das cidades com a intensificação dos processos de urbanização e industrialização e no campo, principalmente, pela presença do agronegócio e pela demora na execução da Reforma Agrária. No entanto, há um forte movimento de reivindicações diretamente ligado às lutas das organizações sociais que defendem a garantia de direitos sociais para os trabalhadores que vivem no e do campo.

Com isso, as reivindicações em favor da Educação do Campo ganharam espaço no debate das políticas públicas para a educação. A melhoria dos níveis de aprendizagem exige mudanças na estrutura política, econômica e social, de forma que garantam a democratização do ensino, de forma que os povos do campo tenham a garantia de acesso a todos os níveis da educação.

Diante disso, este texto apresentou reflexões sobre a formação inicial dos profissionais das escolas do campo por meio da Licenciatura em Educação do Campo ofer- 
tada pela UNIFAP a partir do financiamento do Procampo, possibilitando compreender os princípios fundamentais da Educação do Campo e o itinerário dessa formação. A carência de docentes qualificados para atender as comunidades rurais do Estado do Amapá constitui-se como um dos pontos nevrálgicos que impedem o avanço na qualidade do ensino. Além disso, as condições de trabalho, de ensino-aprendizagem e a infraestrutura de muitas escolas são precárias e marcadas pela falta de material didático, merenda escolar, transporte, dentre outras.

A LEDOC/Procampo veio suprir a lacuna na formação inicial dos docentes, visando elevar a qualidade do ensino nas escolas do campo no País. 0 Procampo foi uma política pontual que serviu de base para a implantação dos cursos regulares de Educação do Campo em 42 IES públicas, inclusive na UNIFAP que, desde 2014, passou a ofertar o curso de LEDOC em Ciências Agrárias e Ciências da Natureza no campus do Município de Mazagão.

Os cursos de Educação do Campo trouxeram para dentro das universidades uma nova concepção e racionalidade sobre as licenciaturas, uma vez que, procuram romper com a forma generalista e fragmentada das graduações tradicionais. Com a LEDOC no contexto amapaense, considera-se que os licenciados são capazes de considerar a mobilização social e a ação coletiva dos povos do campo na construção de uma política social emancipadora que os fazem sujeitos históricos comprometidos com o desenvolvimento socioeconômico do campo.

A análise dos documentos e os registros da pesquisa possibilitaram o entendimento desta formação em Educação do Campo, de um lado, como uma estratégia para a expansão da educação superior e, de outro, como instrumento para qualificar a escola do campo.

Diante disso, pode-se afirmar que para exercer a docência nas escolas do campo do Estado do Amapá é necessário superar inúmeros desafios como a falta de material didático e de docentes com formação adequada, tendo então os cursos do Procampo como meio fundamental de consciência crítica e coletiva sobre a realidade. 0 percurso em um processo de formação acadêmica de professores, naturalmente, vai tornando-se um movimento de ação-reflexão-ação intenso e complexo, que leva os sujeitos a construírem novas relações sociais e profissionais com a sua comunidade.

Portanto, a pesquisa de campo possibilitou o entendimento de que nos cursos do Procampo da UNIFAP todo o processo de formação foi organicamente vivido pelos acadêmicos e professores através de atividades desenvolvidas tanto no âmbito da universidade quanto nas comunidades de origem dos acadêmicos. Nesse processo, os sujeitos do campo têm a oportunidade de compreender a conjuntura histórica das teorias e políticas educacionais e do desenvolvimento rural no contexto amazônico, procurando propor e operar rupturas culturais, sociais, educativas e profissionais em suas convicções e nas concepções que fundamentam sua práxis pedagógica nas escolas do campo. 


\section{REFERÊNCIAS}

ANTUNES-ROCHA, M aria Isabel. Licenciatura em Educação do Campo: histórico e projeto político-pedagógico. In: ; MARTINS, Aracy Alves (Orgs.). Educação do Campo: desafios para formação de professores. Belo Horizonte: Autêntica, 2009.

. Formação de docentes para atuação nas Escolas do Campo: lições aprendidas com as Escolas Normais Rurais. In: MUNARIM , Antônio; BELTRAM E, Sônia; CONTE, Soraya Franzoni; PEIXER, Zilma Isabel (Orgs.). Educação do campo: reflexões e perspectivas. 2. ed. Florianópolis: Insular, 2011.

ARROYO, M iguel Gonzalez. Formação de Educadores do Campo. CALDART, Roseli Salete; PEREIRA, Isabel Brasil; ALENTEJANO, Paulo; FRIGOTTO, (Org.). Dicionário de Educação do Campo. Escola Politécnica de Saúde Joaquim Venáncio. São Paulo: Expressão Popular, 2012.

. Políticas de formação de educadores(as) do campo. Revista CEDES. Campinas, vol. 27, n. 72, p. 157-176, maio/ago. 2007.

BRASIL. Ministério de Educação e Cultura. LDB - Lei no 9394, de 20 de dezembro de 1996. Estabelece as diretrizes e as bases da Educação Nacional. Brasília: M EC, 1996.

ção, 2013.

.M inistério de Educação e Cultura. LDB - Lei no 9394/96. Brasília: MEC, 8a Edi-

. Lei no 10.172, de 9 de janeiro de 2001. Aprova o Plano Nacional de Educação e dá outras providências. Disponível em http://www.mundolegal.com.br/legislação/ LEIS/L10172.htm. Acesso em: 16 jan. 2015.

. Resolução CNE/CEB 1 de 03 de abril de 2002a. Institui Diretrizes Operacionais para a Educação Básica das Escolas do Campo. Disponível em «ttp://www.mec.gov. br. Acesso em: 20 de jan de 2010.

. Resolução MEC/CNE no 2, de 19 de fevereiro de 2002a. Institui a duração e a carga horária dos cursos de licenciatura, de graduação plena, de formação de professores da Educação Básica em nível superior. Disponível em http://portal.mec.gov.br/cne/arqui vos/pdf/2008/rceb002_08.pdf. Acesso em: 14 ago. de 2015.

. Parecer CNE/CEB n 36/2001. Institui Diretrizes Operacionais para a Educação Básica das Escolas do Campo. Disponível em: portal.mec.gov.br/index.php?...di retrizes...educacao-basica. Acesso: 03 out 2015.

- Ministério da Educação. Instituto Nacional de Estudos e Pesquisas Educacionais Anísio Teixeira. Panorama da Educação no Campo. Brasília: INEP, 2007.

Secretaria de Educação Continuada, Alfabetização e Diversidade - Secad. Edital № 9, de 29 de Abril de 2009. Chamada Pública para seleção de projetos de Instituições Públicas de Ensino Superior para o Procampo. Disponível em http://portal.mec.gov.br. Acesso em: 20 set. 2014.

. MEC. Decreto № 7.352, de 4 de novembro de 2010. Dispõe sobre a política de educação do campo e o Programa Nacional de Educação na Reforma Agrária PRONERA. Disponível em http:// www. planalto.gov.br/ . Acesso em: 21 jan. 2015. 
M inistério da Educação. Instituto Nacional de Estudos e Pesquisas Educacionais Anísio Teixeira. Panorama da Educação do Campo. Brasília: INEP, 2015. Disponível em: বhttp://download.INEP.gov.br/educacao_basica/censoescolar/resultadosfor macaodocente/2015/_site_INEP.pdf>. Acesso em: 26 mar. 2016.

M inistério da Educação. Instituto Nacional de Estudos e Pesquisas Educacionais Anísio Teixeira (Inep). Censo Escolar 2012: primeiros resultados. Disponível em: বttp://download.INEP.gov.br/educacao_basica/censoescolar/resultados/2012/_site INEP.pdf>. Acesso em: 30 mar. 2016.

CALDART, Roseli Salete. Pedagogia do Movimento Sem Terra. 3. ed. São Paulo: Expressão Popular, 2004.

Sobre Educação do Campo. In: . Campo, Política Pública e Educação. Brasília: NEAD, 2007. (Coleção Por uma Educação do Campo).

Elementos para construção do Projeto Político e Pedagógico da Educação do Campo. In: M OLINA, M ônica Castagna; JESUS, Sonia Meire Azevedo de (Orgs.). Contribuições para a construção de um projeto de Educação do Campo. Brasília, 2010.

. Licenciatura em Educação do Campo e projeto formativo: qual o lugar da docência por área?. In: M OLINA, M. C.; SÁ, L. M. (Org.). Licenciaturas em Educação do Campo. 1. ed. Belo Horizonte: Autêntica, 2011.

CAM ACHO, Rodrigo Simão. Paradigmas em disputa na educação do campo. Tese (doutorado) - Universidade Estadual Paulista, Faculdade de Ciências e Tecnologia Presidente Prudente: [s.n.], 2014. 806 p.

COSTA, Heliadora Georgete Pereira da. Políticas públicas de educação: um estudo sobre os programas federais de educação para o campo no Amapá. 134 f. Dissertação (M estrado em Desenvolvimento Regional). UNIFAP, M acapá, 2016.

DELGADO, Nelson Giordano. Negociações comerciais internacionais e agricultura familiar no Primeiro Governo Lula. Avanços e Impasses. In: LIMA, E. N. de, DELGADO, Nelson Giordano. e MOREIRA, R. J. (orgs.). Mundo Rural. Configurações RuralUrbanas: Poderes e Políticas. Rio de Janeiro, Ed. UFRRJ/M auad X, p. 171-197, 2005.

DICIONÁRIO PRIBERAM DA LÍNGUA PORTUGUESA. Disponível em http://www.pribe ram.pt/dlpo/catraio [consultado em 21-07-2016].

FERREIRA, Marcos Paulo. Concurso, ingresso e profissão docente: um estudo de caso dos professores de história (São Paulo, 2003-2005). Dissertação (M estrado em História). PUC/SP, São Paulo, 2006.

GATTI, Bernardete A. Formação inicial de professores para a educação básica: pesquisas e políticas educacionais. Estudos em Avaliação Educacional. São Paulo, v. 25, n. 57, p. 24-54, jan./abr. 2014.

LIBÂNEO, José Carlos; PIM ENTA, Selma Garrido. Educação Escolar: Formação de profissionais da educação: visão crítica e perspectiva de mudança. In: CAM ARGO, Elizabeth. Silvares. et al. Formação de profissionais da educação: políticas e tendências. Educação \& Sociedade: Revista quadrimestral de ciência da educação. Campinas: CEDES, Ano XX, no 69, 1999. 
M OLINA, M ônica Castagna (org). Licenciaturas em Educação do Campo e o ensino de Ciências Naturais: desafios à promoção do trabalho docente interdisciplinar. Brasília: MDA, 2014. 268 p. (Série NEAD Debate; 23).

NÓVOA, A. Formação de professores e profissão docente. In: Os professores e sua formação. Portugal: Publicações Dom Quixote - Instituto de Inovação Educacional e autores, 1992.

PALADIM JÚNIOR, Heitor Antônio. Educação do Campo: a territorialização e a espacialização do M ST. São Paulo, SP: ANNABLUM E, 2010.

RAM ALHO, Betania Leite; NUÑEZ, IsauroBeltrán e GAUTHIER, Clermont. Formar o professor, profissionalizar o ensino: perspectivas e desafios. 2. ed., Porto Alegre: Sulinas, 2004.

REIS, Edmerson dos Santos. Educação do Campo: escola, currículo e contexto. Juazeiro/Bahia: ADAC/UNEB-DCH-III/NEPEC-SAB, 2011.

SOUZA, Maria Antônia de. Educação do Campo: Propostas e Práticas Pedagógicas do MST. Petrópolis, RJ. Vozes, 2006.

TAFFAREL, Celi Zulke; SANTOS JR. Claudio de Lira. Desafios da Educação do Campo na UFBA: proposições superadoras - o sistema complexos. In: M OLINA, M. C.; SÁ, L. M. (Orgs.) Licenciaturas em Educação do Campo: registros e reflexões a partir das experiências-piloto. Belo Horizonte: Autêntica, 2011. (Coleção caminhos da Educação do Campo; 5).

UNIFAP. Projeto Memorial do Curso de Licenciatura em Educação do Campo. Macapá, 2010.

- Projeto Político Pedagógico do Curso de Licenciatura em Educação do Campo - Física e Biologia. Macapá, 2011.

VENDRAM INI, Célia Regina. Educação e Trabalho: Reflexões em torno dos movimentos sociais do campo. Cadernos do Cedes/ Centro de Estudos Educação e Sociedade. Educação do Campo, mai./ago. São Paulo, 2007.

Artigo recebido em 11 de outubro de 2016.

Aprovado em 13 de outubro de 2016. 